\title{
É A TEORIA DO SENTIMENTALISMO CONSTRUTIVO DE JESSE PRINZ DE FATO CONSTRUTIVISTA?
}

\author{
Lucas Mateus Dalsotto ${ }^{1}$ \\ Universidade Federal de Santa Maria (UFSM)
}

\begin{abstract}
RESUMO:
Recentemente, a posição construtivista em metaética tem atraído e inspirado uma série de comentários, tanto daqueles que compartilham de suas principais teses e veem-na com entusiasmo, quanto daqueles que a veem com certo ceticismo. Uma das importantes teorias construtivistas nessa área é a de Jesse Prinz. A hipótese central do autor é de que se a moralidade depende dos sentimentos, então ela é uma construção, e se ela é uma construção, então ela pode variar através do tempo e do espaço. A teoria do sentimentalismo construtivo, assim chamada por Prinz, baseia-se em duas premissas centrais, as quais são uma fundamento para a outra. A primeira ideia é de que os sentimentos são a base para todos os juízos de valor que são formulados e que estes mesmos valores podem ser estudados histórica e antropologicamente de modo a explicar porque alguns deles persistem e porque outros têm desaparecido. A segunda ideia é de que os sentimentos criam a moral, e que os sistemas morais podem ser criados espaçotemporalmente de diferentes maneiras. Assim sendo, o problema de trabalho a ser explorado nesse paper é verificar em que medida a teoria de Prinz está de acordo com as principais teses das demais teorias construtivistas e esse não for o caso, por que ela não o faz.
\end{abstract}

PALAVRAS-CHAVE: construtivismo; Sentimentalismo construtivo; Jesse Prinz.

\begin{abstract}
:
Recently, the constructivist position in metaethics has attracted and inspired a number of comments, both those who share its main thesis and see it with enthusiasm, as those who see it with some skepticism. One of the important constructivist theories in this area is that of Jesse Prinz. The central thesis of the author is that if morality depends on feelings, then it is a building, and if it is a building, then it can vary across time and space. The theory of
\end{abstract}

\footnotetext{
${ }^{1}$ Doutorando em filosofia pela Universidade Federal de Santa Maria (UFSM), Rio Grande do sul - Brasil.E-mail: 1mdalsotto@ hotmail.com.
} 
constructive emotionalism, so called Prinz relies on two key assumptions which are a basis for the other. The first idea is that the feelings are the basis for all value judgments that are made and that these values can be studied historically and anthropologically to explain why some of them persist and because others have disappeared. The second idea is that feelings create the moral, and that moral systems can be created in space and time in different ways. Thus, the problem of work to be explored in this paper is to verify to what extent the theory Prinz agrees with the main theses of other constructivist theories and this is not the case, why she does not.

KEYWORDS: Constructivism; Sentimentality constructive; Jesse Prinz.

\section{Apresentação do problema}

Recentemente, a posição construtivista em ética tem atraído e inspirado uma série de comentários, tanto daqueles que compartilham de suas principais teses e veem-na com entusiasmo, quanto daqueles que a veem com certo ceticismo. Em geral, ambos tendem a concordar que as posições construtivistas em filosofia moral e filosofia política são um poderoso e influente grupo de posições filosóficas (DALL'AGNOL , 2012). As teorias de Kant e de Rawls são exemplos paradigmáticos de construtivismo em ética que alcançaram relativo sucesso, a despeito das discordâncias teóricas que eventualmente os respectivos críticos possam vir a ter com relação aos conceitos de cada uma das teorias. Mas o mesmo não se pode dizer com relação ao campo da metaética, uma vez que há profundos desacordos sobre o que fundamentalmente a posição construtivista tem para contribuir à discussão metaética ${ }^{2}$.

Mesmo assim, uma das importantes teorias construtivistas em metaética é a de Jesse Prinz. Já no título de uma de suas obras, The emotional construction of morals, ele sugere que sua teoria seja compreendida como um tipo de construtivismo moral a partir das emoções. Seu pressuposto é de que nossas crenças morais não devem estar baseadas em conjecturas metafísicas ou instâncias transcendentais que possam determinar entre duas concepções morais qual delas é a melhor, mas tão somente em padrões culturalmente aceitos, em convenções sociais (modus vivendi) (PRINZ, 2007). Prinz não adota uma posição niilista, mas sim uma posição subjetivista, relativista e anti-racionalista segundo a qual a moralidade é uma construção humana que deriva de nossos sentimentos (PRINZ, 2007). Em outras palavras, é um tipo de teoria construtivista de caráter convencionalista.

Eu argumentarei que a moralidade deriva de nós. O bom é aquilo que nós elegemos como sendo o bom. O obrigatório é

\footnotetext{
${ }^{2}$ Valho-me aqui da importante discussão realizada por Sharon Street em seu artigo What is Constructivism in Ethics and Metaethics.
} 
aquilo que nós elegemos como sendo o obrigatório. O 'nós' aqui refere-se à pessoa que faz um juízo moral e ao grupo cultural a que esses indivíduo está afiliado. Se o bem é aquilo que nós elegemos como sendo o bom, então nós podemos dizer que nossas obrigações são dadas pelo que nossas crenças morais nos mandam fazer. Descobrir que o que nós acreditamos sobre a moralidade é uma tarefa descritiva par excellence, e que pode ser frutiferamente pesquisada empiricamente. Desse modo, ética normativa pode ser abordada como uma ciência social (PRINZ, 2007, p. 1).

A hipótese central do autor é de que se a moralidade depende dos sentimentos, então ela é uma construção, e se ela é uma construção, então ela pode variar através do tempo e do espaço. A teoria do sentimentalismo construtivo, assim chamada por Prinz, baseia-se em duas premissas centrais, as quais são uma fundamento para a outra. A primeira ideia é de que os sentimentos são a base para todos os juízos de valor que são formulados e que estes mesmos valores podem ser estudados histórica e antropologicamente de modo a explicar porque alguns deles persistem e porque outros têm desaparecido ${ }^{3}$. A segunda ideia é de que os sentimentos criam a moral, e que os sistemas morais podem ser criados espaçotemporalmente de diferentes maneiras.

Assim, a questão que agora se coloca é saber se a teoria de Prinz é de fato uma teoria construtivista e, se este é o caso, em que sentido ela o é. Para tanto, é preciso apresentar, mesmo que de maneira geral, as principais teses de Prinz em sua defesa de uma teoria construtivista baseada no sentimento, de modo que seja possível, num momento subsequente, avaliar se tais teses estão de acordo com as caracterizações correntes a respeito do que seja o construtivismo. É preciso ainda deixar claro que não se pretende defender qualquer tese original ou inovadora no que tange a teoria de Prinz, mas como dito acima, tão somente verificar se sua teoria concorda ou não com as premissas gerais das demais teorias de tipo construtivista.

\section{Elementos fundamentais do sentimentalismo construtivo de Prinz}

Em metaética, existe uma ampla discordância conceitual referente ao modo de como se deve caracterizar posições realistas e não-realistas, naturalistas e não-naturalistas, expressivistas e não-expressivistas. David Copp, em seu livro Morality in a Natural World, fala a respeito disso ao referir-se ao debate entre naturalistas e não-naturalistas no que diz respeito a caracterização do realismo ${ }^{4}$. Por isso, esses mesmo problemas conceituais

\footnotetext{
${ }^{3}$ Prinz (2007, p. 9) também aceita que estes sentimentos podem ter origens biológicas.

${ }^{4}$ David Copp (2007) discute o problema referente ao modo de como o realismo deve ser definido quando ele apresenta o realismo da seguinte maneira: (1) Existem propriedades
} 
de caracterização afetam também o construtivismo, uma vez que existem diferentes maneiras de compreendê-lo. Isso consequentemente acaba gerando duas dificuldades para o construtivismo nas discussões metaéticas: (i) a primeira dificuldade que o construtivismo encontra é que, em sendo uma recente posição, não está inserido em nenhum 'nicho' dentro da metaética, o que dificulta sua aceitação e a ocupação de seu espaço nos debates (ii) e a segunda dificuldade concerne a qual posição o construtivismo ocupa no mapa metaético em relação ao debate entre realismo e anti-realismo.

A despeito desses problemas de caracterização e de aceitação do construtivismo nos debates metaéticos, existem muitos autores em filosofia que utilizam o construtivismo para a justificação de suas teorias, para avaliar que tipo de normatividade tal modelo de justificação implica ou ainda para discutir a verdade ou a não-verdade dos juízos morais. Este crescente número de autores adeptos do construtivismo também propicia o nascimento de diversos tipos de construtivismo. De tipo aristotélico, humeano, kantiano e assim por diante ${ }^{5}$. Entretanto, talvez o modelo mais antigo de construtivismo seja o convencionalismo, o qual afirma que juízos morais são baseados em convenções sociais, isto é, eles são construídos por um acordo de indivíduos ou grupos dentro de tradições específicas. O construtivismo convencionalista, do que Prinz é um dos adeptos, defende que a 'verdade' dos juízos morais e dos padrões do que deve ser feito, são relativos às práticas de grupos específicos.

De modo geral, o construtivismo convencionalista nega o objetivismo defendido pelos naturalistas, quando estes afirmam que fatos morais são como fatos naturais. Por isso, de forma a deixar claro seu argumento, Prinz assume inicialmente a posição contratualistaconvencionalista ${ }^{6}$ de que só é possível falar em objetividade moral se aceitar-se a suposição de que, em um sentido restrito, a moralidade tem um

morais (e relações); (2) Muitas propriedades morais são instantâneas; (3) Predicados morais são utilizados para descrever propriedades morais; (4) Asserções morais expressam crenças morais; (5) Propriedades morais, em sendo propriedades, têm um status metafísico que nenhuma outra propriedade tem, seja lá qual for esse status. Essas cinco asserções são compartilhadas tanto por naturalistas quando por não realistas. O problema é quando os realistas inserem outra cláusula a presente definição, a saber: (6) Propriedades morais são propriedades naturais, o que equivaleria a dizer que a propriedade de ser irritável é uma propriedade 'natural'. Propriedades morais são obviamente importantes de diferentes maneiras das propriedades psicológicas, meteorológicas e econômicas Apesar dessa última cláusula da definição ser passível de algumas controversas, ela é fruto do desacordo interno do realismo entre naturalistas e não-naturalistas.

5 Para ver uma discussão mais profunda a respeito de cada um desses tipos de construtivismo, ver o verbete Constructivism in metaethics na Stanford on-line, o qual foi escrito pela filósofa Carla Bagnoli.

${ }^{6} \mathrm{O}$ tipo de contratualismo-convencionalista que Prinz tem em mente se difere das teorias contratualistas inspiradas por Kant. Embora ele não cite, é possível presumir que esse tipo de constratulismo se parece muito mais com aquele presente em Hobbes.

É a teoria do sentimentalismo construtivo de Jesse Prinz de fato construtivista? - Lucas Mateus Dalsotto 
papel análogo ao da lei. Assim, leis são regras de conduta que têm uma força normativa e que são objetivas na medida em que não dependem das opiniões e atitudes daqueles a quem elas se dirigem. A força normativa de uma lei não está atrelada ao indivíduo realizar o curso de ação X ou Y, mas tão somente no fato de que a lei esteja de acordo com certos procedimentos. Nesse caso, leis são artificiais, do mesmo modo que normas morais o são. Entretanto, Prinz insere uma importante cláusula em seu argumento, afirmando que leis são sempre frutos de produtos intencionais ${ }^{7}$, enquanto convenções morais não são meramente produtos intencionais.

Convenções morais podem advir dos mais variados sentimentos, os quais, na maioria das vezes, não são intencionais. Obviamente, não se entenda aqui intencional no sentido fenomenológico, onde a consciência sempre é intencional, sempre se dirige a alguma coisa, mas sim, como um processo de reflexão racional onde os melhores meios são escolhidos para a execução de um determinado fim. Prinz, no texto Is empathy necessary for morality?, afirma que alguns estudos recentes tem mostrado que, por exemplo, o orgulho e a raiva são sentimentos com uma enorme força motivacional (PRINZ, apud, GOLDIE, 2011). Afirma ainda que tais sentimentos podem ser combinados com outros sentimentos de desaprovação, os quais podem levar indivíduos a inclusive incorrer certos riscos e custos quando estão com raiva de algum ato ou injustiça. Nesse caso, convenções morais podem não ser intencionais, mas simplesmente serem produto de um processo sócio-biológico (PRINZ, 2007).

Mas Prinz refuta essa interpretação objetivista do contratualismoconvencionalista e afirma que o convencionalismo em geral somente poderá ser coerente se adotar os traços de uma teoria subjetivista, negando, nesse caso, qualquer tipo de 'objetivismo'. Segundo o mesmo, "nós devemos desistir do objetivismo moral. Propriedades morais não são objetivas em nenhum senso interessante" (PRINZ, 2007, p. 167). A moralidade não é constituída de características objetivas do mundo da mesma maneira que leões, tigres e ursos o são. Ela deriva exclusivamente de nós (PRINZ, 2007).

Por isso, juízos morais só são verdadeiros analiticamente quando são objetos de sentimentos morais de um determinado indivíduo. Isso porque se juízos morais não são necessariamente intencionais e nesse caso, fruto de determinados procedimentos, então somente uma teoria subjetivo-relativista pode discutir coerentemente sobre a moralidade. Mas o termo relativismo é obviamente ambíguo e pode gerar diversos mal-entendidos, de tal forma que é preciso distinguir entre relativismo descritivo e relativismo metaético. Por um lado, o primeiro tipo de relativismo é usado para sustentar a tese de que em geral as pessoas têm valores morais diferentes e que é possível fazer essa simples constatação empírica por meio de uma análise antropológica. Por outro, o segundo tipo de relativismo, o qual Prinz pretende defender, baseia-

\footnotetext{
${ }^{7}$ Baseados em determinados procedimentos que acarretam na instituição de certas regras.
} 
se na ideia de que as condições de verdade de um julgamento moral dependem do contexto em que esses julgamentos são formados.

No segundo tipo de relativismo, existem dois potenciais contextos a serem considerados. Existe o contexto de quem julga e o outro de quem é julgado. Isso significa dizer que um julgamento que afirma que Carlos deve fazer X é verdadeiro se e somente se é errado não fazer $\mathrm{X}$ a partir do sistema de valores a que Carlos e aquele que realiza o juízo compartilham. O julgamento de que não fazer $\mathrm{X}$ é errado só faz sentido se tal ato for objeto de um sentimento de desaprovação tanto de Carlos quando daquele que emite o juízo.

Prinz entende que, em geral, as pessoas concordam com o relativismo descritivo. Boa parte dos teóricos políticos do século XX entende que essa é umas das características fundamentais das sociedades modernas. Hannah Arendt simplesmente o chama de pluralismo ${ }^{8}$ e John Rawls se refere a ele como sendo o fato do pluralismo?.

De qualquer modo, se o relativismo descritivo é então aceito e, por conseguinte, verdadeiro, Prinz tentará mostrar que o relativismo metaético também o é. Para tanto, ele argumenta da seguinte maneira: partindo-se do pressuposto de que o moralmente correto e incorreto podem ser definidos em termos de sentimentos, uma ação é correta ou incorreta se há um sentimento moral para ela. Esse sentimento moral é uma disposição a respeito de emoções de aprovação ou desaprovação sobre tal ação. Se o relativismo descritivo é verdadeiro, disso se segue que as pessoas têm diferentes sentimentos morais para as mesmas coisas. Nesse caso, se o correto e o incorreto dependem, do ponto de vista metafísico, dos sentimentos que as pessoas têm, então a existência de diferentes sentimentos nas pessoas implica uma diferença nos fatos morais. Por isso, o relativismo metaético pode ser derivado do relativismo descritivo (PRINZ, 2007).

Segundo Prinz, se isso se segue, quando proposições de obrigação (ought) são formuladas, as condições de verdade das mesmas estão relativizadas a aqueles a quem elas se dirigem, uma vez que juízos de deveres são distintos de juízos sobre o correto e o incorreto. Quando eu digo que 'Carlos não deve maltratar seu cachorro' eu estou dizendo mais do que 'maltratar cachorros é errado'. Isso implica que, quando eu digo que Carlos não deve maltratar seu cachorro, existe uma autoridade normativa sobre o comportamento de Carlos e que, por isso, o comportamento de Carlos deveria estar de acordo com esse dever (PRINZ, 2007). Veja-se o exemplo dado por Prinz para elucidar o argumento.

\footnotetext{
${ }^{8}$ Hannah Arendt na obra $A$ Condição Humana argumenta que é a pluralidade ${ }^{8}$ que caracteriza o homem. Se não fossem diferentes, "os homens não precisariam do discurso ou da ação para se fazerem entender" (ARENDT, 2001. p. 188).

${ }^{9}$ Ver RAWLS, 2011.
} 
Presumivelmente missionários acham que o canibalismo é errado. Esse pensamento deve consistir no seu sentimento negativo em relação ao canibalismo. Mas alguma coisa a mais é preciso se eles quiserem que esse sentimento negativo tenha alguma autoridade sobre os Akamara. Por que os Akamara prestariam atenção na norma que condena o canibalismo? Por que deveria essa norma governar suas ações? (PRINZ, 2007, p. 178).

A resposta a essas questões todas depende de qual é a fonte da normatividade. Se normas têm sua autoridade em virtude delas serem universais, no sentido de serem objetivas, então os missionários estão corretos em inferir que a norma contra o canibalismo se aplica aos Akamara. Mas como é sabido, Prinz nega que essa possa ser uma resposta razoável ao problema. Ele afirma que, se normas são locais e dependem dos valores que as pessoas endossam e que, além disso, a qualidade dessas normas depende delas terem sido internalizadas por aqueles a quem elas se dirigem, então a norma contra o canibalismo não tem autoridade sobre os Akamara. Mais ainda, se o conceito de dever está intimamente ligado à ideia de autoridade normativa, logo os missionários estão errados quando dizem que os Akamara devem abster-se do canibalismo, mesmo que eles estejam 'certos' em dizer que o canibalismo é errado de um determinado ponto de vista.

Isso pode ser explicado de maneira mais clara pela tese deôntica ${ }^{10}$ "ought implies can". Julgamentos normativos são declarações de deveres, os quais implicam em declarações de possibilidade que os correspondam. Nesse caso, julgamentos normativos implicam em declarações de possibilidade. Portanto, "alguém deve fazer A somente se ele estiver possibilitado de fazer A" (COHEN, 2008, p. 252), uma vez que a incapacidade humana de realizar A exclui o princípio normativo pelo qual alguém estaria obrigado a fazê-lo. É por isso que as declarações de deveres a respeito do canibalismo dos missionários dirigidas aos Akamara não contém qualquer autoridade normativa, uma vez que estes últimos não têm a possibilidade de modificar imediatamente seus hábitos culturais arraigados já há séculos.

\section{É a teoria de Prinz construtivista?}

\footnotetext{
${ }^{10}$ Won Wright apresenta uma lógica formal das modalidades deônticas a partir de três conceitos, a saber: obrigação (obligation), permissível (permissible) e proibido (forbidden). Ele entende que o único conceito deôntico indefinido que é necessário é o de permissibilidade. Nesse caso, o proibido é então definido em termos do que é permissível e a obrigação é definida em termos do que é proibido. A formalização desses três operadores pode ser feita da seguinte maneira: um ato A é permissível se ele não é proibido. Da mesma forma, um ato A é obrigatório se o agente não está permitido não fazer A (DURAND, 2012).
}

É a teoria do sentimentalismo construtivo de Jesse Prinz de fato construtivista? - Lucas Mateus Dalsotto 
Mas a teoria do sentimentalismo construtivo de Prinz parece encontrar algumas dificuldades dentro dos debates metaéticos atuais, especialmente entre aquelas teorias que se denominam construtivistas. Como dito anteriormente, o modo como o construtivismo deve ser entendido gera alguns problemas tanto com relação a sua posição no debate realismo/não-realismo quanto com relação a própria definição do que o construtivismo venha a ser. Por isso, a pergunta a respeito de se a teoria do sentimentalismo construtivo é de fato construtivista parece retornar.

Darwall, Gibbard e Railton oferecem a seguinte caracterização do construtivismo:

[O] construtivista é um procedimentalista hipotético. Ele endossa um procedimento hipotético que determina quais os princípios que constituem os padrões válidos da moralidade. Esse procedimento pode referir-se a um acordo a respeito de um contrato social, ou pode referir-se também, digamos, a uma decisão a respeito do código moral que deve ser apoiado em uma sociedade. Um procedimentalista mantém, então, que não há fatos morais independente da descoberta de que certo procedimento hipotético teria tais e tais resultados (DARWALL et al, apud, DALL"AGNOL, 2013, p. 42).

Essa definição 'canônica' do construtivismo parece não estar de acordo com a teoria de Prinz, especificamente no que diz respeito ao caráter procedimental das teorias construtivistas. De acordo com essa caracterização prodecimentalista, as regras morais não são meramente descobertas por meio de um procedimento ou resultado dele, mas são constituídas pela emergência desse procedimento. Um exemplo desse tipo construtivismo procedimental pode ser encontrado na teoria da justiça como equidade de John Rawls ${ }^{11}$. Para este último, a moralidade é fruto de um acordo entre indivíduos entendidos como livres, iguais e racionais submetidos ao procedimento da posição original, enquanto que para Prinz a moralidade é fruto de uma construção social baseado nos sentimentos dos indivíduos.

Veja-se também o seguinte. Embora a conclusão que se sugue da caracterização do construtivismo dada acima, a qual diz que não existem fatos morais de modo independente da mente humana, esteja plenamente de acordo com a teoria de Prinz, as semelhanças param por aí. Isso porque o construtivismo subjetivista e relativista de Prinz sabidamente nega a ideia de objetividade, qualquer que ela seja, o que parece ser um pressuposto das teorias construtivistas. O procedimentalismo presente na teoria de Rawls

\footnotetext{
${ }^{11}$ O tipo de procedimentalismo presente em Rawls parte da ideia de que "na justiça procedimental pura os procedimentos oferecem mais do que uma legitimação apenas subsidiária, pois aqui a justiça é ínsita ao próprio procedimento, ao passo que não se pode falar de uma medida independente de procedimentos, quando se objetiva um resultado justo" (HÖFFE, 2003. p. 54).
} 
supõe uma ideia de objetividade e a entende "como um ponto de vista corretamente construído, do qual o contexto fornecido pelo procedimento da posição original é um exemplo" (RAWLS, apud, FREEMAN, 1999, p. 356). Do mesmo modo, esse pressuposto também parece estar presente no construtivismo de Kant na medida em que este defende a ideia de que os princípios da moralidade devem ser objetos de uma escolha racional, livre de quaisquer elementos empíricos, para que assim possam ser universalmente válidos ${ }^{12}$.

Outro ponto problemático da teoria de Prinz é que em determinados aspectos ela parece se enquadrar melhor com teorias emotivistas ou então quasi-realistas do que ao construtivismo como caracterizado por Darwall, Gibbard e Railton. Alguns exemplos disso podem ser expressos pelas teorias de Blackburn e Ayer. O primeiro sustenta que a linguagem moral expressa juízos morais, de modo que as que propriedades morais são peculiarmente supervenientes de uma maneira que só é explicada quando consistem em sentimentos quase-objetivados. No entanto, esses juízos morais não são crenças, uma vez que, ainda que eles aparentemente mostrem-se objetivos, eles não o são de fato (DARWALL et all, apud, DALL'AGNOL, 2013). Já o segundo, por sua vez, é mais radical que o primeiro e sustenta que juízos morais apenas expressam determinados sentimentos de aprovação ou desaprovação, isto é, não expressam proposições, mas somente atitudes emocionais.

Assim, se para Prinz (2007) conceitos morais são sentimentos e se esses sentimentos sobre o certo e o errado somente podem ser analisados na medida em que há uma disposição emocional de aprovação ou desaprovação para tal, então o sentimentalismo construtivo se distância ainda mais do construtivismo procedimentalista. Muito embora exista um amplo debate no interior das teorias emotivistas entre o quasi-realismo de Blackburn e o emotivismo de Ayer, parece que mesmo assim elas acolheriam melhor os pressupostos da teoria de Prinz do que o construtivismo.

\section{A teoria do sentimentalismo construtivo como uma versão do construtivismo metaético humeano}

Todavia, existem alguns autores que afirmam que essa definição dada por Darwall, Gibbard e Railton a respeito do construtivismo não consegue abarcar o pressuposto mais forte dele. Segundo Sharon Street, o construtivismo em metaética pode ser mais bem entendido a partir daquilo

\footnotetext{
12 Kant mesmo ressalta esta questão na Fundamentação da metafísica dos costumes dizendo: "Ora, uma ação por dever deve pôr à parte toda influência da inclinação e com ela todo objeto da vontade, logo nada resta para a vontade que possa determiná-la senão, objetivamente, a lei e, subjetivamente, puro respeito por essa lei prática, por conseguinte a máxima de dar cumprimento a uma tal lei mesmo com derrogação de todas as minhas inclinações". (KANT, 2009. Ak, 400).
} 
que ela chama de caracterização de um ponto de vista prático (practical standpoint characterization). Seu argumento é de que embora não se tenha certeza do que seja o valor, as pessoas sabem o que significa valorar, pois o mundo está cheio de indivíduos que valoram coisas. Quando alguém valora algo, ela ocupa uma posição daquilo que Street chama de um ponto de vista prático. Isto significa que o ponto de vista prático pode ser ocupado por qualquer criatura que toma o mundo como sendo bom ou mau, melhor ou pior, enfim, que assume o ponto de vista de alguém que julga (STREET, 2010).

Além de ter uma compreensão do que significa o ato de valorar, as pessoas também compreendem a ideia de vinculação (entailment) a partir de dentro de um ponto de vista prático de um dado conjunto de valores. Para além do fato de se achar que um determinado conjunto de valores seja correto, ainda que não se saiba o que faz com que ele assim o seja, é possível pensar e discutir o que disso se segue como uma questão puramente lógica e formal. $\mathrm{O}$ exemplo de Street é um tanto extravagante, mas auxilia no entendimento do argumento. É possível dizer que Ann está equivocada em supervalorizar o ato de contar folhas de grama, mas a partir de dentro do seu ponto de vista valorativo, Ann tem uma razão para comprar uma calculadora. Isso quer dizer que a ideia de vinculação (entailment) não precisa pressupor em si mesma nenhuma noção normativa, nem mesmo fazer nenhuma consideração normativa substancial a respeito do que alguém deveria fazer. Precisa apenas fazer observações sobre o que está constitutivamente envolvido na atitude de valorar (STREET, 2010).

Street então caracteriza o construtivismo em metaética de acordo com a ideia de que a "verdade de uma afirmação normativa consiste em que essa reivindicação seja vinculada de dentro de um ponto de vista prático, onde o ponto de vista prático é dado por uma caracterização formal" (STREET, 2010, p. 369). Entendido dessa maneira, o construtivismo pode ser distinguido entre versões kantianas e humeanas. Ambas as versões concordam que a verdade de uma afirmação normativa consiste em ela estar vinculada a partir de dentro de um ponto de vista prático, onde este ponto é dado por uma caracterização formal. $\mathrm{O}$ aspecto de desacordo entre tais versões é sobre se conclusões morais se seguem a partir de dentro de um ponto de vista prático. Para as versões kantianas, se seguem. A teoria de Christine Korsgaard presente em The Sources of Normativity é um exemplo dessa visão.

Mas para as versões humeanas não ${ }^{13}$. E é exatamente esse ponto que parece abrir possibilidades para uma melhor compreensão do sentimentalismo construtivo de Prinz, uma vez que ele mesmo entende sua teoria como herdeira de Hume (STREET, 2010). Se a caracterização procedimentalista do construtivismo colocava em cheque o construtivismo

${ }^{13}$ Ver WONG, 2006. 
de Prinz, talvez a caracterização de Street recoloque a teoria de Prinz entre o rol de teorias construtivistas.

Segundo Street, o que as versões humeanas negam é fato de que conclusões morais substantivas possam ser vinculadas a partir de dentro de um ponto de vista prático. Elas afirmam que o conteúdo substantivo das conclusões morais de um determinado agente é construído em função de suas particulares dadas contingencialmente. Nesse caso, a ideia de razão prática pura não vincula nenhum valor substantivo específico. Em vez disso, esses valores substantivos devem "finalmente ser fornecidos pelo conjunto particular de valores com o qual alguém encontra a si mesmo vivo como um agente" (STREET, 2010, p. 370). Se as versões kantianas do construtivismo metaético vindicam uma forma muito forte de universalismo a respeito de razões morais, as versões humeanas negam que o coelho das razões substantivas possa ser tirado de uma cartola formalista.

Visto dessa maneira, a caracterização do construtivismo sugerida por Street está plenamente de acordo com a teoria de Prinz, pois a premissa central de ambas as teorias se coadunam. Elas concordam que, embora a verdade de uma afirmação normativa consista em que essa reivindicação seja vinculada de dentro de um ponto de vista prático, o conteúdo substantivo dos juízos morais apenas podem advir de um conjunto de valores com o qual um indivíduo entra em contato subjetivamente. Nesse caso, conforme a caracterização do construtivismo sugerida por Street, a teoria do sentimentalismo construtivo de Prinz é uma versão humeana do construtivismo em metaética.

\section{Considerações finais.}

Como buscou-se mostrar, há uma extensa discussão a respeito de se teorias construtivistas têm algo a dizer a respeito dos debates metaéticos, e se tiverem, como elas responderiam às antigas questões de tais debates (DARWALL et al, apud, DALL'AGNOL, 2013). A definição sobre o construtivismo dada por Darwall, Gibbard e Railton, em princípio, exclui todo o tipo de teoria não-procedimental, isto é, que não adota um determinado procedimento do qual regras e princípios possam ser derivados. Teorias construtivistas somente fariam sentido enquanto uma família de teorias substantivas. Mas como se mostrou a partir da leitura de Street, essa caracterização não parece capturar os aspectos mais fundamentais e próprios do construtivismo. Ela nega qualquer possibilidade de construtivismo em metaética.

Nesse caso, se a leitura a propósito de como se deve caracterizar o construtivismo de Street está correta, então a o sentimentalismo construtivo de Prinz se enquadra perfeitamente como uma versão humeana de construtivismo em metaética. Obviamente sua teoria é passível de análise tanto do ponto de vista de se é possível uma teoria construtivista relativo- 
subjetivista, quanto do ponto de vista de quão bem ela responde às antigas questões metaéticas. No entanto, embora haja um intenso desacordo sobre esses temas, parece adequado dizer que a teoria do sentimentalismo construtivo de Prinz não deixa de ser uma produtiva tentativa de construtivismo em metaética ou então que tenha importantes intuições relativamente à natureza da moralidade e ao modo como ela se constitui socialmente. Ela reforça o fato de que as teorias construtivistas não tem apenas algo a dizer à filosofia moral ou à filosofia política, mas também à metaética.

\section{Referências bibliográficas}

ARENDT, Hannah. A condição humana. 10.ed. Rio de Janeiro: Forense Universitária, 2001

COHEN, Gerald A. Rescuing justice and equality. Cambrigde: Harvard University Press, 2008.

COPP, David. Morality in a Natural World. Cambridge: Cambridge University Press, 2007.

DALL'AGNOL, Darlei (Org.). Metaética: algumas tendências. Florianópolis: Ed. da UFSC, 2013.

DURAND, Kevin. K. J. The Logic of Morality: Georg Henrik von Wright, Immanuel Kant, and the "Ought/Can" Inference. Acessado em: 24/06/2014. Disponível

em :http://www.hsu.edu/uploadedFiles/Faculty/Academic_Forum/20001/20001 AFThe\%20Logic\%20of\%20Morali.pdf HÖFFE, Otfried. O que é justiça? Porto Alegre: EDIPUCRS, 2003.

PRINZ, Jesse J. The emotional construction of morals. Oxford: Oxford University Press, 2007

. Is empathy necessary for morality? In: COPLAN, Amy e GOLDIE, Peter (Eds). Empathy: philosophical ans psychological perspectives. Oxford: Oxford University Press, 2011.

RAWLS, John. O Liberalismo político. 1 ed. amp. São Paulo: M. Fontes, 2011.

Kantian constructicvism in moral Theory. FREEMAN, Samuel. Collected Papers. Cambridge: Cambridge University Press, 1999. STREET, Sharon. What is Constructivism in Ethics and Metaethics?, Philosophy Compass 5/2010, pp. 363-384.

WONG, David. Natural Moralities: a Defense of Pluralistic Relativism. Oxford: Oxford University Press, 2006. 